\title{
Transformasi memajukan industri kecil dan sederhana (IKS) di kalangan wanita luar bandar
}

\author{
Zurinah Tahir ${ }^{1}$, Jalaluddin Abdul Malek ${ }^{1}$, Sivapalan Selvadurai ${ }^{1}$, Yusof Hussain ${ }^{1}$ \\ ${ }^{1}$ Program Sains Pembangunan, Pusat Pembangunan, Sosial dan Persekitaran, \\ Fakulti Sains Sosial dan Kemanusiaan, Universiti Kebangsaan Malaysia \\ Correspondence: Zurinah Tahir (email: zurinahtahir@ukm.edu.my)
}

Received: 27 May 2019; Accepted: 13 October 2019; Published: 25 November 2019

\begin{abstract}
Abstrak
Kesedaran komuniti setempat tentang pentingnya keterlibatan wanita luar bandar dalam Industri Kecil dan Sederhana (IKS) sangat membantu negara dalam memajukan ekonomi negara. Sememangnya tidak dapat dinafikan, ramai golongan wanita di negara ini telah menyumbang dalam pembangunan ekonomi negara, maka langkah pemerkasakan ekonomi wanita luar bandar penting bukan sahaja dalam ekonomi malah untuk meningkatkan kesejahteraan hidup. Oleh itu, kajian ini memfokuskan kemajuan Industri Kecil dan Sederhana (IKS) yang menyumbang kepada pendapatan wanita luar Bandar di Jelebu Negeri Sembilan dengan menganalisis strategi ke arah memajukan lagi sektor IKS. Kajian ini menggunakan kaedah kuantatif yang melibatkan seramai 152 responden. Hasil dapatan kajian mendapati strategi 'Mencari peluang yang ada' dan 'Berusaha untuk meningkatkan perniagaan' adalah amat penting dalam kesedaran di kalangan wanita luar bandar untuk memajukan sektor IKS. Strategi memperkasa kemajuan IKS penting dalam memberi ruang kepada golongan wanita daripada pelbagai latarbelakang untuk perkongsian idea, pengalaman serta aspirasi dan secara tidak langsung mempromosikan produk sama ada di peringkat tempatan mahupun peringkat global. Sememangnya banyak produk yang dihasilkan daripada sektor IKS adalah bermutu tinggi. Apabila ada strategi dan langkah memperkasa ini dilaksanakan serta bantuan daripada agensi kerajaan, diyakini produk IKS ini akan dapat dipasarkan secara meluas. Keadaan ini sudah tentu memberi peluang kepada usahawan wanita untuk mengetahui peluang yang wujud di sekeliling bagi mengembangkan lagi perniagaan ke arah peringkat global dan akhirnya menyumbang kepada pembangunan ekonomi negara.Development in this manner could enable women entrepreneurs to be aware of the opportunities available for the expansion of their businesses globally, ultimately contributing to the development of the national economy.
\end{abstract}

Kata kunci: ekonomi, industri kecil dan sederhana (IKS), luar bandar, pembangunan, transformasi, wanita 


\title{
Transformation to promote small and medium industries (SMIs) among rural women
}

\begin{abstract}
Community awareness of the importance of involving rural womenfolk in Small and Medium Industries (SMIs) could assist in the economic development of the country. It is undeniable that women have contributed substantially to the advancement of the national economy, and the call to intensity the involvement of rural womenfolk is not only important to the economy, but it is also a path to raising their quality of life. Hence, a study was undertaken on the development of Small and Medium Industries (SMIs) that have the potential to contribute to the income of rural women in Jelebu, Negeri Sembilan. Adopting a quantitative method involving 152 respondents, we analysed various strategies to advance the SMI sector. The results indicated that calling on rural womenfolk to 'Seek all available opportunities' and 'Strive to uplift your business' are important in creating an awareness of the potential of SMIs to provide business opportunities. The expansion of SMIs provides a platform for women from various backgrounds to share their ideas, experiences and aspirations, and in so doing, indirectly promote products for the local or global market. Undoubtedly, many products from the SMI sector are of a high quality. With such a strategy in place and with aid forthcoming from governmental agencies, there is good reason to believe that SMI products can be marketed more widely. Women entrepreneurs should avail themselves of the opportunities provided to build businesses of global standing, and at the same time, contribute to the national economy.
\end{abstract}

Keywords: economy, small and medium industries (SMIs), rural, development, transformation, women

\section{Pengenalan}

Di Malaysia pihak kerajaan dan swasta memainkan peranan yang penting dalam menarik minat masyarakat di negara ini untuk menceburi bidang Industri Kecil dan Sederhana (IKS) khususnya di kalangan luar bandar. Sektor IKS ini dianggap penting memandangkan ia memberikan sumbangan yang besar kepada pendapatan negara yang dapat melahirkan usahawan berjaya. Usahawan yang berjaya bukan sahaja mencipta perniagaan baru malahan meningkatkan peluang pekerjaan yang menjurus kepada sumber penciptaan penemuaan terbaru, teknologi baru dan inovasi.

Dalam usaha membangunkan sektor IKS dan aktiviti keusahawanan di luar bandar, pihak kerajaan Malaysia telah memberi tumpuan yang sepenuhnya dengan melibatkan pelbagai kementerian dan institusi seperti Kementerian Pembangunan Usahawan, Kementerian Pembangunan Luar Bandar dan Wilayah, Kementerian Pembangunan Wanita, Keluarga dan Masyarakat dengan kerjasama institusi seperti Majlis Amanah Rakyat (MARA) (Nor Azira et al., 2016), Amanah Ikhtiar Malaysia (AIM), SME Bank, Tabung Ekonomi Usaha Niaga (TEKUN), UDA Holdings Bhd, Bank Pembangunan, Perbadanan Nasional Berhad (PNS), Bank Rakyat, Jabatan Pembangunan Koperasi (JPK), Maktab Kerjasama Malaysia (MKM) dan Syarikat Pembangunan Ekonomi Negeri (SEDCs) (Ummi Munirah Syuhada et al., 2017). 
Penglibatan wanita sememangnya tidak asing lagi dalam sektor IKS. Hal ini kerana terdapat beberapa faktor yang mendorong wanita terlibat secara tidak langsung dalam sektor IKS antaranya ialah faktor kos sara hidup yang tinggi, ekonomi keluarga dan peluang pekerjaan sebagai usahawan. Selain itu, golongan wanita merupakan sebahagian besar daripada populasi masyarakat Malaysia yang memainkan peranan besar dalam memberi sumbangan kepada ekonomi negara. Keperluan peranan wanita itu telah memaksa mereka untuk melakukan sesuatu bagi menambah lagi hasil pendapatan sama ada berkepentingan terhadap individu atau yang sudah bekeluarga. Tidak dapat dinafikan, golongan wanita pada masa kini perlu mempunyai pekerjaan, dan sektor IKS ini dilihat sebagai peluang besar kepada mereka. Sektor IKS ini memberi ruang dan peluang kepada golongan wanita kerana banyak cabang pekerjaan yang diperolehi oleh wanita seperti pembuatan beras, perkilangan, menyediakan penghasilan makanan dan sebagainya yang dapat meningkatkan pendapatan, ekonomi dan kualiti hidup mereka.

Isu penyertaan golongan wanita di luar bandar dalam bidang keusahawanan di peringkat nasional dan atarabangasa khususnya dalam sektor IKS semakin sering ditekankan. Selaras dengan agenda pembangunan ekonomi dan sosial untuk mewujudkan sebuah bangsa Malaysia yang bersatu padu dan kental pada masa hadapan, penekanan perlu diberi kepada aspek agihan pendapatan yang seimbang dan keadilan sosial di kalangan masyarakat bandar dan luar bandar. Masyarakat luar bandar sering dianggap tersisih dan jauh ketinggalan di belakang dalam semua aspek berbanding dengan masyarakat bandar. Oleh itu, golongan luar bandar khususnya wanita, kini perlu mengambil inisiatif untuk melakukan perubahan dan transformasi yang drastik dari semua aspek khususnya dari segi pemikiran dan mentaliti untuk meceburi bidang keusahawanan bagi meningkatkan kekuatan dan kemantapan ekonomi untuk bersaing secara sihat dan tidak terus ketinggalan menuju negara berpendapatan tinggi.

Keterlibatan golongan wanita dalam sektor IKS dilihat sebagai sesuatu yang positif terhadap perkembangan ekonomi negara. Seiring kaum lelaki, wanita juga tidak melepaskan peluang untuk turut sama memeriahkan lagi sektor ini di Malaysia. Perkembangan pesat ekonomi negara menggamit lebih ramai golongan wanita untuk melibatkan diri secara aktif dalam dunia IKS. Pada zaman sekarang, di seluruh dunia terdapat ramai wanita yang menceburi sektor IKS telahpun menjadi jutawan yang terkenal. Malah, sebahagian darinya dilihat lebih agresif dari lelaki dari segi fikiran, perasaan dan tindakan.

Dalam dunia perniagaan, wanita ternyata mempunyai kelebihan yang tersendiri jika dibandingkan dengan kaum lelaki. Wanita lebih bersedia menghadapi ragam pelanggan dan tekun menguruskan perniagaan. Contoh kegiatan usahawan yang terdiri dari golongan wanita adalah Kumpulan Ekonomi Wanita (KEW) yang diwujudkan oleh Jabatan Perikanan daerah Langkawi. Kumpulan Ekonomi Wanita (KEW) ini telah memberi peluang pekerjaan kepada wanita di Kuala Teriang untuk menambah pendapatan keluarga dengan terlibat dalam bidang keusahwanan. Usahasama dan inisiatif daripada Jabatan Perikanan, maka satu industri kecil dan sederhana (IKS) telah dibina di kampung ini melalui Kumpulan Ekonomi Wanita (KEW) tentang pentingnya meningkatkan peranan golongan wanita luar bandar agar menjadi lebih aktif dan peka dalam mengendalikan pemprosesan ikan untuk dijadikan sumber pendapatan. KEW ini juga ditubuhkan untuk meningkatkan pendapatan isi rumah golongan nelayan supaya para isteri tidak perlu bergantung sepenuhnya kepada pendapatan suami dan diberi peluang untuk menjana pendapatan sendiri agar lebih berdikari dan berdaya saing (Nur Hafizah \& Rahimah, 2012).

Justeru, dalam ekonomi mencabar pada masa kini, tidak hairanlah sektor IKS memainkan peranan penting dalam kehidupan golongan wanita. Isu kewangan sering menghambat sesebuah institusi kekeluargaan dan pelbagai cabaran seperti menangani peningakatan kos sara hidup tinggi telah mendorong ramai golongan wanita yang telah menceburi sektor IKS untuk menjana pendapatan keluarga dan ekonomi rumahtangga. Hal 
demikian, tidak dapat dinafikan, ramai wanita di negara ini telah menyumbang dalam pembangunan ekonomi negara. Oleh itu, kemajuan perniagaan di kalangan wanita luar bandar Malaysia perlu dititikberatkan kerana wanita merupakan aset negara bagi pertumbuhan ekonomi negara.

\section{Kajian literatur}

\section{Transformasi memajukan IKS di kalangan wanita luar bandar}

Penglibatan golongan wanita dalam industri kecil dan sederhana (IKS) adalah hampir satu pertiga di Malaysia. Sumbangan dan peranan wanita sama ada sebagai isteri, ibu serta pekerja yang mempunyai gaji, di dalam pembangunan negara adalah amat penting dan tidak boleh dinafikan sama sekali. Golongan wanita bukan sahaja memainkan peranan utama di dalam pembentukan generasi pada masa akan datang malah merupakan sebahagian sumber ekonomi yang penting khususnya penglibatan mereka dalam sektor IKS (Nur Hafizah \& Rahimah, 2012). Di sektor IKS luar bandar, golongan wanita terus memainkan peranan penting sebagai guna tenaga yang terlibat secara tidak langsung dalam memajukan sektor ini. Oleh kerana peri pentingnya peranan golongan wanita dalam sektor IKS, maka program transformasi memajukan IKS di kalangan wanita luar bandar wajar diperkasa untuk meningkatkan pembangunan ekonomi komuniti dan negara.

Program transformasi memajukan IKS di kalangan wanita luar bandar merupakan satu program Desa Lestari di bawah pembangunan Desa Abad ke 21 oleh KKLW. Fokus utama pogram ini ialah untuk mentransformasikan desa dengan tumpuan terhadap sektor pembangunan ekonomi komuniti. Kampung yang mendapat projek Desa Lestari akan dimajukan dengan pelbagai projek ekonomi berdaya maju demi meningkatkan pendapatan usahawan desa. Selain itu ia membuka peluang pekerjaan kepada penduduk kampung yang lain terutama kepada para belia dan golongan wanita (Jalaluddin \& Zurinah, 2018).

Proses transformasi sosial ekonomi desa biasanya mengalami tiga tahap perubahan. Proses pertama bermula pada tahap tradisional di mana kesedaran terhadap kemajuan masih perlahan iaitu urus diri (endogenous) manusia tidak begitu mencabar. Selanjutnya, faktor urus sistem (exogenous) atau pengaruh luaran yang masih dalam lingkungan tradisi. Pembangunan desa yang dilakukan seadanya dengan pembangunan sosio ekonomi berdasar kepada konsep sara diri dan bersifat usaha kerja kekeluargaan. Tahap kedua, berlaku proses peralihan sebelum berlakunya proses transformasi. Ada tiga jenis proses transisi pembangunan luar bandar, pertama tansisi yang berlaku secara evolusi perlahan iaitu perubahan yang berlaku secara beransur-ansur. Kedua transisi yang berlaku secara evolusi cepat, iaitu perubahan yang berlaku secara cepat, pantas dan mungkin tergesa-gesa. Manakala yang ketiga transisi pembangunan luar bandar yang berlaku secara melalui proses perubahan semulajadi budaya sesuatu individu dan kelompoknya (Daniela, 2015). Dalam menuju tahap transformasi ekonomi luar bandar ini, transisi pembangunan memerlukan pendekatan evolusi yang lebih pantas untuk kemajuan ekonomi. Sehubungan itu, tahap transformasi untuk pembangunan luar bandar yang mapan memerlukan anjakan paradigma yang bersifat reformis dan menyeluruh. Proses tranformasi berlaku bukan sahaja disebabkan oleh faktor dari model exogenous dan model endogenous tetapi juga oleh faktor dari model neo-exogenous dan model neo-endogenous (Mohd Azuhari \& Jalaluddin, 2016). Gabungan empat model dan faktor tadi timbul kembangan penekanan terhadap pembangunan mapan terutama bila berdepan dengan proses globalisasi dan perkembangan teknologi termaju. Sehubungan itu, proses transformasi yang berkesan dalam pembangunan mapan memerlukan faktor kebangkitan, visi, pendekatan, pembelajaran serta kerjasama atau muafakat (Shucksmith, 2009). 
Realisasi transformasi untuk pembangunan ekonomi luar bandar yang mapan boleh tercapai melalui lima faktor kejayaan. Pertama, adanya rasa kebangkitan dan kesedaran jati diri dalam kalangan penduduk desa. Kedua, pemerintah, birokratik, penduduk desa serta pihak berkepentingan lain mempunyai visi yang jelas untuk membangun kawasan luar bandar terbabit. Ketiga, munculnya pendekatan yang paling sesuai dan diterima oleh pentadbir, pelaksana dan penerima pembangunan luar bandar seperti model neo-exogenous dan neoendogenous sehingga mereka begitu faham untuk melaksana strategi pembangunan. Keempat, semua pihak yang terlibat bersedia menjadi masyarakat pembelajaran di mana masyarakat itu mahu belajar, menerima dan berkongsi ilmu untuk kemajuan pembangunan luar bandar. Kelima, penyertaan pembangunan oleh pihak yang berkepentingan disertai dengan rasa mahu memberi kerjasama yang maksimum serta bersedia untuk bermuafakat sama ada semasa proses perancangan, pelaksanaan dan pemantauan. Jaringan manual dan jaringan siber merupakan instrumen utama menyokong proses pemuafakatan dalam pembangunan luar bandar (Mohd Azuhari \& Jalaluddin, 2016).

\section{Pendekatan Model Neo Endogenous dan Neo Exogenous dalam memajukan IKS luar bandar}

Pembangunan ekonomi luar bandar khususnya sektor IKS oleh golongan wanita telah melalui berbagai pendekatan dalam merangka kejayaan untuk mencapai matlamat khususnya memajukan ekonomi. Pendekatan transformasi memajukan ekonomi luar bandar yang awal di kebanyakan negara membangun adalah melalui pendekatan model exogenous dan endogenous. Model exogenous merupakan kefahaman bahawa pertumbuhan ekonomi timbul disebabkan pengaruh luar ekonomi atau syarikat yang menarik perkembangan industri luar bandar (Jalaluddin \& Zurinah, 2018). Pertumbuhan ekonomi ditentukan oleh faktor-faktor luaran dan bukan faktor dalaman. Model exogenous melihat kejayaan melalui faktor-faktor luaran seperti sistem politik, sistem pasaran dan suasana global. Manakala endogenous adalah melalui proses input dalaman seperti sikap, nilai dan motivasi. Model ini menyatakan bahawa peningkatan modal insan sesebuah negara akan membawa kepada pertumbuhan ekonomi melalui pembangunan bentuk baru teknologi, inovasi dan kecekapan serta pengeluaran yang efisyen (Margarian, 2011).

Oleh sebab itu, transformasi sosio ekonomi untuk memajukan sektor IKS di kalangan wanita dapat dilaksanakan dengan penerapan melalui pendekatan model exogenous, endogenous, neo exogenous dan neo endogenous dalam melaksana pembangunan ekonomi luar bandar. Model neo exogenous merupakan kefahaman terhadap teori ekonomi yang menggariskan bagaimana kadar pertumbuhan ekonomi seimbang boleh dicapai melalui tiga faktor utama iaitu buruh, modal dan teknologi (Gkartzios \& Scott, 2013). Model neo exogenous menekankan bahawa perubahan teknologi mempunyai pengaruh yang besar ke atas pertumbuhan ekonomi dan akhirnya membawa kepada kemajuan teknologi yang lebih maju. Manakala, model neo endogenous pula merupakan kepercayaan terhadap idea pembangunan berdasarkan kepada sumber dalaman dan sumber luaran. Sumber dalaman adalah ciri-ciri unik individu dan masyarakat. Sumber luaran melibatkan penguasaha negeri, pertubuhan bukan kerajaan, institusi swasta dan organisasi yang tidak berasas keuntungan. Begitu juga dua jenis sumber pengetahuan memainkan peranan penting dalam metod neo endogenous iaitu pertama adalah sumber luaran seperti pengetahuan pakar disumbangkan oleh pakar dan wakil institusi berkenaan. Kedua, sumber pengetahuan tempatan, disumbangkan oleh cerdik pandai masyarakat setempat serta berdasarkan pengalaman dan tradisi setempat (Jalaluddin \& Zurinah, 2018). Komponen dan indikator pendekatan pembangunan luar bandar iaitu model exogenous, endogenous, neo-exogenous dan neoendogenous adalah ditunjukkan pada Jadual 1. 
Jadual 1. Komponen model exogenous, endogenous, neo-exogenous dan neo-endogenous

\begin{tabular}{llll}
\hline \multicolumn{1}{c}{ Exogenous } & \multicolumn{1}{c}{ Endogenous } & \multicolumn{1}{c}{ Neo-exogenous } & \multicolumn{1}{c}{ Neo-endogenous } \\
\hline Kestabilan politik & Personaliti & Kecekapan governance, & Aktor kreatif dan inovatif \\
Kestabilan ekonomi & Sikap dan diri & human governance, & dan berwawasan \\
Kelengkapan Infrastruktur & Motivasi & intelligent governance, & Muafakat dan jaringan \\
Persekitaran \& alam sekitar & Pendidikan \& & Keberkesanan program & dalaman dan jaringan luar \\
& pengetahuan & CSR, sistem pemuafakatan, & Berdaya tahan \\
& Kemahuan dan & Kemajuan dan kemanusiaan & Masyarakat berdikari dan \\
& kehendak & teknologi termaju sistem & berwawasan \\
& & Nyah pusat yang cekap & Berpaksi kemajuan \\
& & & berterusan \\
\hline
\end{tabular}

Sumber: Jalaluddin \& Zurinah, 2018

\section{Metodologi}

Kajian ini menggunakan pendekatan kaedah kuantitatif sepenuhnya dengan menggunakan instrumen soal selidik untuk menganalisis strategi transformasi memajukan IKS di kalangan wanita luar bandar. Kawasan kajian adalah di Mukim Kuala Klawang, Daerah Jelebu Negeri Sembilan yang melibatkan responden seramai 152 orang Penduduk Daerah Jelebu. Semua responden diambil dari kawasan kajian di Mukim Kuala Klawang yang menjalankan kegiatan sektor IKS. Antara kegiatan IKS yang dijalankan adalah pembuatan makanan, kuih muih, kerepek, kuih tradisional, kiosk, makanan sejuk beku, peruncitan makanan dan katering makanan dan minuman. Semua responden 152 orang adalah terdiri dari kalangan wanita di kawasan kajian. Setiap responden diedarkan dengan borang soal selidik bagi mendapatkan maklumat yang diperlukan. Hasil soal selidik yang dijawab oleh responden, dianalisis menggunakan frekuensi analisis deskriptif. Kawasan responden melibatkan 9 buah kampung di sekitar daerah Jelebu Negeri Sembilan, iaitu Kampung Kemin, Kampung Petasih, Kampung Binjai, Kampung Tembun, Kampung Triang, Kampung Chepom, Kampung Peradong, Kampung Dulang dan Kampung Larong.

\section{Penemuan kajian dan perbincangan}

Penglibatan golongan wanita dalam sektor industri kecil dan sederhana (IKS) penting dalam pembangunan sosioekonomi luar bandar. Usaha yang berterusan harus ditumpukan ke arah menambah bilangan projek ekonomi wanita yang terus berdaya maju untuk menyokong kepada kemajuan luar bandar. Hasil penemuan kajian mendapati aspek 'Kesedaran diri sendiri' mencatat purata skor min tertinggi iaitu 4.34 yang menjadi pencetus utama dalam transformasi strategi memajukan sektor IKS di kalangan wanita luar bandar (Jadual 2). Transformasi memajukan IKS di kalangan wanita adalah sangat penting menerusi kesedaran diri mereka sendiri untuk memajukan IKS. Aspek 'Kesedaran diri sendiri' adalah merangkumi item 'Motivasi diri tentang perusahaan yang dihasilkan (4.33), Mencari peluang yang ada (4.38), Disiplin tinggi dalam mengendalikan perniagaan (4.31), Kehendak dan kemahuan diri sendiri (4.32), Berusaha untuk meningkatkan perniagaan (4.36), dan Meningkatkan ilmu dan pengetahuan keusahawanan (4.34)'.

Motivasi diri tentang perusahaan yang dihasilkan adalah penting dalam memajukan perniagaan yang diceburi. Golongan wanita perlu lebih berinovasi dan peka terhadap keperluan dalam perusahaan yang dijalankan dan berani mengambil risiko (Norashidah et al., 2009). Golongan wanita perlu menceburkan diri dalam dunia perniagaan dengan berusaha mencari peluang tidak kira walau hanya perniagaan keluarga yang diusahakan secara kecil- 
kecilan, mereka perlu berusaha bersungguh-sungguh untuk memajukannya. Selain itu, mereka perlu mempunyai displin yang tinggi dan perlu komited terhadap setiap kerja yang dilakukan serta berazam untuk berjaya dalam bidang keusahawanan dan berusaha mengembangkan perusahaan. Bagi memantapkan diri mereka dalam sektor IKS, golongan wanita haruslah komitmen untuk menghadiri pelbagai kursus yang dianjurkan oleh pihak yang berkenaan seperti MARDI, MARA, MADA, FAMA dan SIRIM. Disiplin tinggi dalam mengendalikan perniagaan adalah penting untuk meeka terus megorak langkah dalam bidang perniagaan sektor IKS ini. Golongan wanita juga perlu meningkatkan ilmu dan pengetahuan keusahawanan dalam usaha untuk memajukan sektor IKS luar bandar. Sifat malas dan takut menimba ilmu menjadi antara faktor ramai usahawan IKS luar bandar tidak mengambil peluang yang disediakan kepada mereka. Usahawan wanita khususnya dalam industri IKS sepatutnya sedar tanpa ilmu mereka tidak mungkin dapat mengembangkan perniagaan dengan baik. Usahawaan wanita perlu mempunyai gaya kepimpinan dan keupayaan dalaman diri dengan berani meneroka perniagaan baru (Zaimah \& Sazuani, 2017) dan sentiasa proaktif dalam meningkatkan kemajuan perniagaan mereka (Imran Shafique, 2016). Ini adalah bertepatan dengan definisi keusahawanan itu sendiri iaitu merangkumi aspek sikap, nilai, pengetahuan dan kemahiran yang membolehkan seseorang itu cekap dalam mencari, mengenal dan merebut peluang dan menterjemahkannya kepada strategi dan langkah-langkah untuk faedah ekonomi dan mendapatkan keuntungan. Justeru, sikap kesedaran dalam keusahawanan itu menjadi faktor penting bagi pertumbuhan ekonomi yang mampu menggerakkan segala aktiviti perniagaan yang dijalankan (Nor Azira et al., 2016). Ia juga bertepatan dengan pendekatan model transformasi sosio ekonomi yang dapat dilaksanakan dengan penerapan melalui pendekatan model endogenous yang merangkumi personaliti, sikap dan diri, motivasi, pendidikan dan pengetahuan serta kemahuan dan kehendak dalam perubahan untuk memajukan sektor IKS di kalangan wanita luar bandar.

Aspek perolehan dana dan modal menunjukkan purata skor min kedua tertinggi (4.34) bagi strategi memajukan IKS di kalangan wanita luar bandar. Hasil keputusan analisis mendapati item 'Pihak swasta/kerajaan perlu memberi sokongan dari segi modal/dana (4.34) dan Pengusaha mencari inisiatif untuk mendapatkan bantuan kewangan (3.32)' mencatat tahap kepentingan yang tinggi. Keperluan untuk memperolehi dana dan modal amat penting dalam memajukan sektor ini di mana pihak swasta atau kerajaan perlu memberi sokongan dari segi modal dan dana kepada usahawan wanita untuk memajukan sektor IKS luar bandar. Terdapat pelbagai kemudahan pinjaman yang disediakan kepada pengusaha IKS antaranya termasuklah institusi kewangan kerajaan, bank komersial dan syarikat kewangan. Pihak kerajaan menawarkan pelbagai bentuk bantuan pembiayaan kepada pengusaha IKS. Bantuan ini disalurkan melalui agensi-agensi bertanggungjawab dan juga melalui institusi-institusi kewangan. Di samping itu, pihak kerajaan dan swasta turut menawarkan geran dan insentif kepada pengusaha IKS antaranya termasuklah Skim kewangan di bawah Kementerian Perdagangan Antarabangsa dan Industri (MITI), Perbadanan Pembangunan Industri Kecil \& Sederhana (SMIDEC), Perbadanan Pembangunan Perdagangan Luar Malaysia (MATRADE), Perbadanan Produktiviti Negara (NPC), Lembaga Kemajuan Perindustrian Malaysia (MIDA), Kementerian Pembangunan Usahawan dan Koperasi (MECD), Kementerian Pertanian dan Industri Asas Tani (MOA), Kementerian Sains, Teknologi dan Inovasi (MOSTI), Kementerian Kemajuan Bandar dan Wilayah (KPLB) dan juga Skim geran penyelidikan dan pembangunan Koridor Raya Multimedia (MSC). Selain itu, usahawan wanita perlu mencari inisiatif sendiri untuk mendapatkan bantuan kewangan dalam memajukan sektor IKS. Sebagai contoh program bantuan/inisiatif kerajaan seperti program Pembangunan Keushawanan Wanita (Dewi) sebagai langkah pemerkasaan ekonomi wanita memberi fokus kepada wanita untuk meningkatkan ekonomi juga kesejahteraan hidup. Bank Negara Malaysia turut mengumumkan penubuhan Unit Khas Industri Kecil dan Sederhana (IKS) 
bagi mambantu untuk pengusaha maendapatkan pembiayaan kewangan. Unit Khas ini membantu syarikat IKS yang berdaya maju untuk memperolehi pembiayaan. Selain sistem perbankan sebagai wadah penyedia utama pembiayaan kepada IKS, terdapat sumber-sumber pembiayaan alternatif termasuklah institusi kewangan pembangunan dan pelbagai dana khas yang disediakan oleh kerajaan untuk memajukan sektor IKS. Perolehan dana dan modal amat penting sebagai strategi memperkasa IKS di kalangan wanita luar bandar dan membina sebuah komuniti usahawan wanita yang mempunyai sokongan padu dan mengembangkan sosioekonomi secara mapan.

Jadual 2. Strategi Memajukan IKS di kalangan wanita luar bandar

\begin{tabular}{|c|c|c|c|}
\hline Bil & Item & $\begin{array}{l}\text { Skor } \\
\text { Min }\end{array}$ & $\begin{array}{c}\text { Tahap } \\
\text { Kepentingan }\end{array}$ \\
\hline \multirow[t]{6}{*}{$\mathbf{1}$} & Teknik pemasaran yang baik & $* 4.28$ & Tinggi \\
\hline & i. Melaksanakan promosi pasaran dengan efisien & 4.26 & Tinggi \\
\hline & ii. Pemasaran yang berterusan & 4.26 & Tinggi \\
\hline & iii. Mendekati pelanggan dengan lebih dekat & 4.31 & Tinggi \\
\hline & iv. Pengusaha mempunyai pengetahuan yang baik mengenai produk & 4.33 & Tinggi \\
\hline & v.Mengembangkan pasaran produk dengan lebih luas & 4.23 & Tinggi \\
\hline \multirow[t]{5}{*}{2.} & Inovatif dan kreatif & $* 4.24$ & Tinggi \\
\hline & i. Perlu mempelbagaikan aktiviti ekonomi & 4.21 & Tinggi \\
\hline & ii. Kreatif dalam memasarkan produk yang dihasilkan & 4.23 & Tinggi \\
\hline & iii. Perlu berwawasan dalam memajukan produk yang dihasilkan & 4.25 & Tinggi \\
\hline & iv. Produk mempunyai ciri-ciri keistimewaan sendiri & 4.28 & Tinggi \\
\hline \multirow[t]{5}{*}{3.} & Meningkatkan kemahiran dan pengetahuan & $* 4.18$ & Tinggi \\
\hline & $\begin{array}{l}\text { i. Menghadiri bengkel/taklimat khusus mengenai bidang penghasilan } \\
\text { mereka }\end{array}$ & 4.16 & Tinggi \\
\hline & ii. Mempunyai modul bisnes sendiri & 4.07 & Tinggi \\
\hline & iii. Mempunyai perancangan yang teliti dalam mencapai sasaran & 4.22 & Tinggi \\
\hline & iv. Mempunyai pengetahuan yang luas mengenai bidang mereka & 4.25 & Tinggi \\
\hline \multirow[t]{9}{*}{4} & Mewujudkan jaringan kerjasama & $* 4.20$ & Tinggi \\
\hline & (a)dalaman & & \\
\hline & i. institusi kewangan & 4.31 & Tinggi \\
\hline & ii. Kerjasama dengan agensi pemasaran & 4.22 & Tinggi \\
\hline & iii. Koperasi dikalangan peniaga & 4.15 & Tinggi \\
\hline & iv. Kerjasama dengan agensi penyelidikan & 4.17 & Tinggi \\
\hline & (b)luaran & & \\
\hline & i. Karnival dianjurkan oleh FAMA & 4.07 & Tinggi \\
\hline & ii. Karnival MAEPS & 4.26 & Tinggi \\
\hline \multirow[t]{3}{*}{5} & Perolehan dana/modal & $* 4.33$ & Tinggi \\
\hline & i. Pengusaha mencari inisiatif untuk mendapatkan bantuan kewangan & 4.32 & Tinggi \\
\hline & $\begin{array}{l}\text { ii. Pihak swasta/kerajaan perlu memberi sokongan dari segi } \\
\text { modal/dana. }\end{array}$ & 4.34 & Tinggi \\
\hline \multirow[t]{7}{*}{6} & Kesedaran diri sendiri & $* 4.34$ & Tinggi \\
\hline & i. Motivasi diri tentang perusahaan yang dihasilkan & 4.33 & Tinggi \\
\hline & ii. Disiplin tinggi dalam mengendalikan perniagaan & 4.31 & Tinggi \\
\hline & iii. Mencari peluang yang ada & 4.38 & Tinggi \\
\hline & iv. Kehendak dan kemahuan diri sendiri & 4.32 & Tinggi \\
\hline & v. Meningkatkan ilmu dan pengetahuan keusahawanan & 4.34 & Tinggi \\
\hline & vi. Berusaha untuk meningkatkan perniagaan & 4.36 & Tinggi \\
\hline
\end{tabular}

Nota: * =Purata Skor Min

Seterusnya, strategi 'teknik pemasaran yang baik' menunjukkan purata skor min ketiga tertinggi iaitu 4.28 (Jadual 2). Item dalam strategi teknik pemasaran yang baik merangkumi 'Pengusaha mempunyai pengetahuan yang baik mengenai produk (4.33), Mendekati pelanggan dengan lebih dekat (4.31), Pemasaran yang berterusan (4.26), Melaksanakan 
promosi pasaran dengan efisien (4.26), dan Mengembangkan pasaran produk dengan lebih luas (4.23)'. Usaha mengembangkan pasaran produk dengan lebih luas penting untuk mempromosikan produk dengan lebih komersial. Sebagai contoh inisiatif kerjasama kerajaan dalam membantu usahawan wanita memasarkan produk adalah melalui Projek 1nita. Projek ini bertujuan untuk memperkasakan IKS yang diterajui wanita melalui perkembangan teknologi dan menyertai ekonomi dan pasaran global ke arah meningkatkan potensi dan hasil perniagaan. Ia juga dapat membantu perniagaan milik wanita untuk memasarkan produk dan perkhidmatan mereka ke pasaran yang lebih besar serta memperluaskan capaian pelanggan. Projek ini juga membolehkan IKS yang diterajui oleh golongan wanita dapat menyumbang dalam mencapai aspirasi strategi ekonomi negara. Aktiviti-aktiviti yang dijalankan dalam Projek 1nita antaranya adalah perkongsian pengetahuan dan latihan, dan yang lebih penting ia menjadi asas untuk mencapai hasil perniagaan yang optima.

Aspek 'Inovatif dan kreatif' juga merupakan strategi penting dalam transformasi memajukan sektor IKS di kalangan wanita luar bandar. Aspek strategi ini merangkumi item 'Perlu mempelbagaikan aktiviti ekonomi (4.21), Kreatif dalam memasarkan produk yang dihasilkan (4.23), Perlu berwawasan dalam memajukan produk yang dihasilkan (4.25), Produk mempunyai ciri-ciri keistimewaan sendiri (4.28)'. Golongan usahawan wanita luar bandar perlu mengenalpasti ciri-ciri keistimewaan produk meraka supaya lebih komersial dan mempunyai nilai tambah yang membezakan produk lain supaya terus kekal di pasaran. Golongan wanita juga perlulah kreatif dalam mempelbagaikan produk mereka. Mereka juga perlu kreatif dalam memasarkan produk yang dihasilkan. Ia dapat dihasilkan dengan menerapkan kaedah penggunaan ICT menerusi internet di samping memaksimumkan sepenuhnya kemudahan teknologi dalam aktiviti perniagaan mahu pun aktiviti seharian mereka untuk memasarkan produk dan memperkenalkan produk kepada umum secara meluas. Penelitian terhadap kemajuan perkembangan ICT di luar bandar haruslah dititik beratkan memandangkan kemajuan ICT ini dapat membantu aktiviti perniagaan mereka dan mengubah taraf hidup wanita di luar bandar khusisnya agar terlibat dalam sektor IKS secara berterusan (Siti Masayu Rosliah, 2016).

Hasil penemuan kajian menunjukkan strategi 'Mewujudkan jaringan kerjasama' mencatat purata skor min (4.20). Kerjasama ke arah transformasi memajukan IKS di kalangan wanita luar bandar melibatkan dua jaringan kerjasama iaitu dalaman dan luaran. Bagi jaringan kerjasama dalaman ia adalah melibatkan institusi kewangan (4.31), kerjasama dengan agensi pemasaran (4.22), kerjasama dengan agensi penyelidikan (4.17), koperasi di kalangan peniaga (4.15). Kerjasama ini perlu melibatkan inisiatif kerajaan untuk memberi laluan kepada usahawan industri kecil dan sederhana (IKS) khususnya di kalangan wanita luar bandar bagi mempromosi dan memasarkan produk keluaran mereka di tempatan dan antarabangsa. Syarikat multinasional (MNC) dan syarikat besar tempatan (LLC) perlu memainkan peranan lebih besar membantu pengusaha Industri Kecil dan Sederhana (IKS) tempatan mengembangkan perniagaan dalam industri halal ke peringkat antarabangsa. Selain itu, jaringan hubungan yang baik antara MNC serta LLC dengan IKS tempatan adalah penting kerana ia dapat membantu pengusaha dalam industri itu mengembangkan pasaran perniagaan mereka ke luar negara. Kerjasama ini mungkin dalam bentuk membantu IKS menaik taraf proses dan penghasilan produk mereka melalui pemindahan teknologi terutama dalam aspek kritikal seperti teknikal dan komersial supaya ia dapat menembusi pasaran antarabangsa. Ini sekali gus dapat membantu akses IKS tempatan ke pasaran eksport utama yang biasanya lebih mencabar dan mempunyai tuntutan yang pelbagai. Kerjasama dengan pihak dalaman dan luaran dalam memperkasa IKS adalah perlu dalam memupuk usahawan wanita supaya berdaya saing dan juga mahir berkenaan transaksi e-dagang. Kerjasama ini juga dilihat sebagai platform jaringan untuk manfaat optimum memajukan perniagaan di kalangan usahawan wanita luar bandar. 
Strategi 'Meningkatkan kemahiran dan pengetahuan' dengan purata skor min (4.18) juga dilihat memainkan peranan penting dalam memperkasa sektor IKS di kalangan wanita luar bandar. Menerusi analisis kajian (Jadual 2) mendapati responden bersetuju akan perlunya untuk menghadiri bengkel atau taklimat khusus mengenai bidang penghasilan (4.16), mempunyai modul bisnes sendiri (4.07), mempunyai perancangan yang teliti dalam mencapai sasaran (4.22), dan mempunyai pengetahuan yang luas mengenai bidang mereka (4.25). Penglibatan golongan wanita dalam IKS dapat dilaksanakan secara berterusan dengan meningkatkan bengkel kemahiran dan strategi pemasaran, bantuan kewangan, menambah khidmat nasihat daripada agensi pembangunan, dan mendapat sokongan kuat daripada suami serta keluarga untuk meningkatkan ekonomi mereka. Ini juga disokong dengan pendekatan model neo-endogenous iaitu faktor penglibatan persatuan wanita dengan mempunyai modul bisnes sendiri dan perancangan teliti dilihat penting dalam menggalakkan kemajuan program keusahawanan dan IKS di kalangan wanita luar bandar. Sebagai contoh Projek 1nita adalah satu platform e-perniagaan yang dibangunkan khusus untuk Industri Kecil dan Sederhana (IKS) yang diterajui dan dipimpin oleh usahawan wanita bagi meningkatkan keupayaan dan kemahiran mereka dalam ICT di samping menyediakan mereka dengan platform untuk menjalankan perniagaan online. Inisiatif 1nita juga adalah satu pendekatan berinovasi untuk usahawan wanita bukan sahaja berniaga secara dalam talian, malah dapat memperluaskan jangkauan pasaran produk dan perkhidmatan mereka. Selain itu, ia bertujuan untuk memberi kemahiran dan pengetahuan untuk membina perniagaan dalam talian yang berjaya melalui latihan dan bengkel. Dengan menyertai Projek 1nita, usahawan wanita akan dapat menikmati faedah-faedah seperti sesi latihan dan bengkel keusahawanan, kecekapan untuk membangunkan laman sesawang bagi memudahkan urusan perniagaan, memuat naik dan mengemas kini kandungan dan transaksi dalam talian, mempunyai laman sesawang yang mantap dengan kandungan seperti profil syarikat, produk dan perkhidmatan yang ditawarkan, mendapat faedah yang boleh diukur dari kehadiran web dalam masa setahun selepas program dan juga mempunyai URL .my untuk identiti syarikat yang unik. Adalah amat penting untuk golongan usahawan wanita luar bandar mempunyai pengetahuan yang luas mengenai bidang perniagaan. Mereka boleh menghadiri persidangan untuk meningkatkan lagi pengetahuan supaya menjadi landasan mendapatkan galakan dan dorongan bagi meningkatkan lagi keuntungan perniagaan pada masa hadapan. Contoh persidangan yang boleh dihadiri termasuklah Persidangan Ekonomi Wanita Malaysia di mana mereka dapat berkongsi pengalaman akan kejayaan usahawan wanita lain dalam bidang perniagaan dan pembangunan ekonomi. Menerusi persidangan ini golongan wanita akan dapat berdiri setaraf dengan golongan lelaki dalam industri perniagaan dan wanita akan lebih bijak menguruskan kewangan, dapat belajar mengenai cara untuk menjadi seorang eksekutif serta peluang dan peranan wanita dalam transformasi ekonomi luar bandar.

Penglibatan golongan wanita dalam sektor keusahawanan IKS ini dilihat sebagai keupayaan dalam menyumbang pendapatan yang signifikan kepada penduduk wanita dan keluarga mereka dalam jangka panjang. Ini bermakna, ia bukan sahaja memberi pendapatan atau sekurang-kurangnya mengurangkan kemiskinan, tetapi juga dapat memberi pekerjaan kepada wanita dan keluarga mereka serta individu lain di luar bandar dan juga dapat meningkatkan ekonomi. Jika transformasi strategi memperkasa sektor IKS dilaksanakan berterusan, sudah tentu penglibatan wanita dalam sektor ini akan semakin bertambah dari masa ke masa. 


\section{Kesimpulan}

Transformasi memajukan sektor IKS di kalangan wanita luar bandar perlu dilaksanakan untuk pembangunan ekonomi negara dan usaha ini harus berterusan dilaksanakan untuk menambahbaik kualiti kehidupan masyarakat sesebuah kampung. Strategi memperkasa sektor IKS di kalangan wanita luar bandar dapat dilaksanakan dengan usaha yang dijalankan oleh pihak kerajaan dan swasta bersama dengan inisiatif masyarakat setempat untuk meningkatkan kualiti kehidupan dan pertumbuhan ekonomi kampung. Hasil kajian keseluruhan mendapati semua aspek dan item adalah pada tahap kepentingan yang tinggi. Maka strategi memperkasa pembangunan sektor IKS di kalangan wanita luar bandar perlu didasari dengan aspek 'kesedaran diri sendiri, diikuti strategi perolehan dana/modal, teknik pemasaran yang baik, inovatif dan kreatif, mewujudkan jaringan kerjasama dan meningkatkan kemahiran dan pengetahuan'. Transformasi memajukan sektor IKS penting dalam meningkatkan pencapaian golongan wanita adalah menerusi saluran ekonomi iaitu industri IKS. Kepentingan IKS luar bandar ini telah membuka peluang pekerjaan yang lebih banyak kepada golongan wanita, dan meningkatkan sumber pendapatan mereka serta taraf hidup. Oleh itu, secara tidak langsung sumbangan golongan wanita dalam sektor IKS luar bandar dapat membantu dalam meningkatkan ekonomi negara dan meningkatkan kemahiran tenaga kerja serta membantu dalam proses pemindahan teknologi dan inovasi dalam melahirkan usahawan berjaya di peringkat tempatan dan antarabangsa.

\section{Rujukan}

Daniela, A. (2015). Theoretical approaches of endogenous regional development. Institute of National Economy. Munich Personal RePEc Archive (MPRA) Paper No. 64679, posted 31. May 2015 12:21 UTC

Gkartzios, M., \& Scott, M. (2013). Placing Housing in Rural Development: Exogenous, Endogenous and Neo-Endogenous Approaches. European Society for Rural Sociology. Sociologia Ruralis, 2013.

Imran, S. (2016). Leadership styles and corporate entrepreneurship: Small and medium enterprises in Pakistan. PhD thesis, University of Malaya.

Jalaluddin Abdul Malek, \& Zurinah Tahir. (2018). The Neo-Exogenous and Neo-Endogenous Models in Malaysian Rural Transformation in the 21st Century. pp.1717-1724. Information: An lnternational lnterdisciplinary Journal, 21(6), 1717-1724.

Margarian, A. (2011). Endogenous Rural Development: Empowerment or Abandonment?. Paper presented at the 4th International Summer Conference in Regional Science, Dresden, June 30-July 1, 2011.

Mohd Azuhari Che Mat, \& Jalaluddin Abdul Malek. (2016). Model pembangunan neoendogenous luar bandar dan faktor sokongan koperasi: Kajian kes program desa lestari di Malaysia. Geografia-Malaysian Journal of Society and Space, 12(1), 75-84.

Nor Azira Ayob, Sity Daud, Muhamad Takiyuddin Ismail. (2016). Faktor pembentukan modal insan dan daya saing usahawan wanita Malaysia: Kajian empirikal wanita bumiputera di Melaka. Geografia-Malaysian Journal of Society and Space, 12(5), 115129.

Norashidah Hashim, Norasmah Othman, \& Noraishah Buang. (2009). Konsep Kesediaan Keusahawanan Berdasarkan Kajian Kes Usahawan Industri Kecil dan Sederhana (IKS) di Malaysia. Jurnal Pendidikan Malaysia, 34(1), 187-203.

Nur Hafizah Yusoff, \& Rahimah Abdul Aziz. (2012). Pemerkasaan wanita desa: Kajian ke atas Kumpulan Ekonomi Wanita (KEW), Kuala Teriang, Langkawi, Kedah. Geografia- 
Malaysia Journal of Society and Space, 8(6), 15-23.

Shucksmith, M. (2010). Disintegrated Rural Development? Neo-endogenous rural development, planning and place-shaping in diffused power contexts. Sociologia Ruralis, 50: 1-14. https://doi.org/10.1111/j.1467-9523.2009.00497.x

Siti Masayu Rosliah Abdul Rashid. (2016). Keupayaan ICT dalam meningkatkan pencapaian usahawan wanita: satu kajian kes usahawan luar bandar di Malaysia. e-Bangi Journal, 11(2), 78-103.

Ummi Munirah Syuhada, M.Z., Aidatul Najwa, H.A., Mohammed Rizki, M., Wan Suraya, W.H., \& Wan Shahzlinda, S.S. (2017). Faktor-Faktor yang Mempengaruhi Kejayaan Usahawan Wanita Tekun: Satu Kajian di Daerah Hulu Langat. Proceeding of the 4th International Conference on Management and Muamalah 2017 (ICoMM 2017).

Zaimah, R., \& Sazuani, A. (2017). Tahap keupayaan usahawan dalam Perusahaan Kecil dan Sederhana di Kuala Terengganu. Geografia-Malaysian Journal of Society and Space, 13(4), 117-125. 